\title{
THE IMPACT OF MEDICATION REGIMEN COMPLEXITY ON ADHERENCE TO LONG-TERM THERAPIES
}

\author{
SHAKEEL AHMAD MIR ${ }^{1}$, DANISH SHAKEEL ${ }^{2}$ \\ ${ }^{1}$ Department of Clinical Pharmacology, Sher-I-Kashmir Institute of Medical Sciences (SKIMS), Srinagar, Jammu and Kashmir, India \\ ${ }^{2}$ Department of Computer Science Engineering, University Institute of Engineering, Chandigarh University, Mohali, Punjab, India. \\ Email: drshakeelahmadmir@gmail.com
}

Received: 24 May 2021, Revised and Accepted: 30 June 2021

ABSTRACT

Objective: Adherence is a multifactorial phenomenon. Medication-related factors have long been the focus of attention. However, the results are inconsistent.

Methods: In a cross-sectional questionnaire-based study of outpatients, we assessed 180 patients suffering from chronic conditions. The objective of this study is to determine the impact of medication regimen complexity on adherence to long-term drug therapies.

Results: $91.66 \%$ of patients receiving more than four drugs had good or high adherence. 80.94\% of patients on thrice a day (or more) drug administration had good or high adherence. $91.66 \%$ of patients receiving drug therapy for more than 5 years had good or high adherence. In all other groups, the adherence was low. The adherence was significantly $(\mathrm{p}<0.05)$ and positively (rs $=0.792$ and 0.846$)$ correlated to the frequency of drug administration and duration of treatment. Adherence was positively correlated to the number of drugs per day (rs=0.668) but the relationships were not statistically significant ( $\mathrm{p}=0.102)$. All the correlations were large.

Conclusions: We found adherence positively correlated with medication regimen complexity. An improved understanding of the determinants of medication adherence is needed.

Keywords: Medication regimen complexity, Adherence, Long-term therapy, Chronic disease.

(C) 2021 The Authors. Published by Innovare Academic Sciences Pvt Ltd. This is an open access article under the CC BY license (http://creativecommons.org/ licenses/by/4.0/) DOI: http://dx.doi.org/10.22159/ajpcr.2021v14i9.42304. Journal homepage: https://innovareacademics.in/journals/index.php/ajpcr

\section{INTRODUCTION}

The WHO defines adherence to long-term therapy as the extent to which a person's behavior-taking medication, following a diet, and/or executing lifestyle changes-correspond with agreed recommendations from a healthcare provider [1].

Adherence is a key factor in the efficacy of all pharmacological therapies, but it is especially critical for drugs prescribed for chronic diseases. Non-adherence is a serious problem that affects both the patient and the health care system [2].The factors commonly involved in non-adherence can be divided into five different types: Social and economic factors, treatment-related factors, disease-related factors, patient-related factors, and health system factors [3]. The important treatment-related factor is medication regimen complexity.

The complexity of a drug regimen consists of many characteristics of the prescription regimen, including but not limited to the number of drugs in the regimen, the number of doses per day, the number of dosage units per dose, and the total number of units per day [4].

Although more complex medication regimens are generally believed to lead to reduced compliance, the evidence supporting this association is conflicting. Many studies show that the more drugs a person takes, the lower the adherence. However, some researchers have observed the opposite [5]. This study aims to examine the relationship between medication regimen complexity and adherence to long-term drug therapies. Understanding the relationship may lead to better health outcomes.

\section{METHODS}

The descriptive questionnaire-based study was conducted in a time span of 4 months from November 2020 to February 2021, among patients attending the outpatient department of SKIMS Hospital, Kashmir, India.

\section{Study population}

A total of 225 patients selected by simple randomization were given a pre-validated questionnaire out of which only 189 returned it. Nine of them had answered incompletely hence data of only 180 participants were considered for the study.

\section{Inclusion criteria}

Suffering from chronic disease, ability to communicate by at least one of the means viz. speaking or writing, consuming medicine under doctor's prescription for at least last 1 year, age more than 18 years.

\section{Exclusion criteria}

Suffering from acute disease, unable to communicate by at least one of the means viz. speaking or writing, taking prescribed drugs for $<1$ year, age less than 18 years.

\section{Study tools}

Pre-tested questionnaire which was prepared in English and Urdu. It had three sections. Section one included the questions about the demographics such as age, gender, location, educational qualification, income, etc. Section two had questions about disease and prescribed medications. Section three asked questions about medication adherence. 
Research instrument

The research instrument to assess therapeutic adherence used in this study was the English and Urdu versions of the General Medication Adherence Scale (GMAS). The scale consists of 11 multiple choice questions with four possible options divided into three components. Component 1 measures adherence based on patient behavior while the $2^{\text {nd }}$ component measures adherence based on comorbidity and pill burden. The third measures adherence based on cost. Each item carries an individual score that ranges from 0 to 3 . The sum of all 11 individual item scores yields cumulative adherence for a patient that is categorized as high (30-33), good (27-29), partial (17-26), low (11-16), and poor adherence $(\leq 10)[6]$.

\section{Data analysis}

Data were entered and analyzed using VassarStats and SPSSv22. Multiple linear regression analysis was used to evaluate the correlation between the drug-therapy-related factors and medication adherence. Internal consistency was assessed using Cronbach's alpha. Descriptive and comparative statistics were used to describe adherence and drug therapy-related characteristics. We set a significance level $(\alpha)$ value of 0.05 .

\section{RESULTS}

Table 1 shows that the study population consists of $46.7 \%(n=84)$ males and $53.3 \%(n=96)$ females. $20.0 \%(n=36)$ participants were $20-40$ years old, $36.66 \%(n=66) 41-60$ years and $43.33 \%(n=78)$ were above 60 years

Table 2 shows that $40.0 \%(n=72)$ participants were taking a single drug, $53.3 \%(n=96) 2-4$ drugs, and $6.7 \%(n=12)$ more than 4 drugs. $73.3 \%$ $(\mathrm{n}=132)$ were taking prescribed $\operatorname{drug}(\mathrm{s})$ once a day, $15.0 \%(\mathrm{n}=27)$ twice a day and $11.7 \%(n=21)$ thrice a day or more. $66.66 \%(n=120)$ had treatment duration of $1-5$ years and $33.33 \%(n=60)$ more than 5 years.

Table 3 shows that among those on one drug $2.27 \%(n=2)$ had poor, and $97.22 \%(n=70)$ had low adherence. Those on $2-4$ drugs, $3.12 \%(n=3)$ had poor, $40.62 \%(n=39)$ low, $4.16 \%(n=4)$ partial and $52.08 \%(n=50)$ good adherence. Among the patients receiving more than 4 drugs, 8.33\% ( $n=1)$ had partial, 66.66\% $(n=8)$ good and 25.0\% $(n=3)$ high adherence. Those on once a day regimen, showed poor adherence in $10.60 \%(n=14), 75.75 \%(n=100)$ low, $1.51 \%(n=2)$ partial and $12.12 \%$ $(n=16)$ good adherence. Those on twice a day regimen, showed partial adherence in $25.92 \%(n=7)$ and $74.07 \%(n=20)$ good adherence. Those on Thrice a day or more regimen had partial adherence in $19.04 \%$ $(n=4)$, good adherence in $66.66 \%(n=14)$ and high adherence in $14.28 \%(n=3)$. Patients with treatment duration of $1-5$ years, showed poor adherence in $11.66 \%(n=14)$, low adherence in $83.33 \%(n=100)$, and partial adherence in $1.2 \%(\mathrm{n}=1)$. Those on treatment for more than 5 years, had partial adherence in $8.33 \%(n=5)$, good adherence in $86.66 \%(n=52)$ and high adherence in $5.0 \%(n=3)$.

Table 4 shows spearman correlation between adherence and other therapy-related independent variables.A correlation of 0.846 between adherence and treatment duration, 0.668 between adherence and number of drugs, 0.792 between adherence and frequency of drug administration.

Table 5 shows regression analysis results.R square was 0.723 and two out of three independent variables significantly $(\mathrm{p} \leq 0.05)$ predict target variables.

\section{DISCUSSION}

Adherence is a key factor in all pharmacological therapies but is particularly important for the drugs used in chronic diseases [2]

Despite the evidence that medication improves quality of life and reduces death, people with chronic diseases have adherence rates of only $50-60 \%$ [7].
Table 1: Demographics of study population

\begin{tabular}{lll}
\hline Sex & No & \% \\
\hline Male & 84 & 46.7 \\
Female & 96 & 53.3 \\
\hline Age-wise distribution & & \\
\hline Age Group & No. & $\%$ \\
\hline 20-40 years & 36 & 20.0 \\
41-60 years & 66 & 36.66 \\
Above 60 years & 78 & 43.33 \\
\hline
\end{tabular}

Table 2:Drug therapy received by study population

\begin{tabular}{lcc}
\hline Number of drugs prescribed & & \\
\hline No. of drugs & No. & $\%$ \\
\hline One drug & 72 & 40.0 \\
2-4 drugs & 96 & 53.3 \\
$>4$ drugs & 12 & 6.7 \\
\hline \multicolumn{3}{c}{ Frequency of Drug administration } \\
\hline Frequency & No. \\
\hline Single daily dose & 132 & $\%$ \\
Twice a day & 27 & 73.3 \\
Thrice a day or more & 21 & 15.0 \\
\hline & Treatment duration & 11.7 \\
\hline Duration & No. & \\
\hline$<5$ year & 120 & $\%$ \\
\hline 5 year & 60 & 33.33 \\
\hline
\end{tabular}

Various factors related to adherence include: social and economic factors, therapy-related factors, disease-related factors, patient-related factors and health care system-related factors [3]. The impact of drug type and number, on medication adherence in chronic conditions has been extensively researched. Despite widespread belief that adherence will drop as the number of medications taken increases, studies on the relationship between the total number of prescribed drugs and adherence have produced mixed results.

In many studies, the impact of therapy-related parameters (duration of therapy, amount of drugs, frequency of consumption), and the effect of duration of illness on adherence was uncertain [3]. Some studies have shown that adherence decreases when patients are prescribed multiple medications while other researchers have found that the adherence rises as the number of prescribed medications grows [5].

Using a regression model with number of drugs, frequency of drug administration, and duration of treatment as the independent variables, and adherence score as the target variable - we achieved an R-Squared value $=0.723$, Adjusted R-Squared value $=0.719$, and Std. Error of Estimate $=0.276$.

The ANOVA table shows that independent variables statistically significantly predict the target variable, $\mathrm{F}(3,176)=153.438, \mathrm{p}<0.05$. Using the coefficients table, the equation to predict the target variable is:

Predicted Adherence Score $=0.310+(0.292 *$ duration of treatment $)+(0.594 *$ drugs $)+(0.161 *$ frequency $)$.

Using the coefficients, we can deduce that two variables (frequency of drug admininistration and duration of treatment) are statistically significant at $\mathrm{p}<0.05$. 
Table 3: Adherence as per GMAS

\begin{tabular}{|c|c|c|c|c|c|}
\hline Drugs & Poor & Low & Partial & Good & High \\
\hline One drug & $2(2.77)$ & $70(97.22)$ & 0 & 0 & 0 \\
\hline $2-4$ drugs & $3(3.12)$ & $39(40.62)$ & $4(4.16)$ & $50(52.08)$ & 0 \\
\hline$>4$ drugs & 0 & 0 & $1(8.33)$ & $8(66.66)$ & $3(25.0)$ \\
\hline \multicolumn{6}{|l|}{ Frequency } \\
\hline Once a day & $14(10.60)$ & $100(75.75)$ & $2(1.51)$ & $16(12.12)$ & 0 \\
\hline Twice a day & 0 & 0 & 7 (25.92) & $20(74.07)$ & 0 \\
\hline Thrice a day or more & 0 & 0 & $4(19.04)$ & $14(66.66)$ & $3(14.28)$ \\
\hline \multicolumn{6}{|l|}{ Duration of Rx } \\
\hline $1-5$ years & $14(11.66)$ & $100(83.33)$ & $1(1.2)$ & $5(4.16)$ & 0 \\
\hline$>5$ years & 0 & 0 & $5(8.33)$ & $52(86.66)$ & $3(5.0)$ \\
\hline
\end{tabular}

GMAS: General Medication Adherence Scale

Table 4: Spearman correlations (rs)

\begin{tabular}{|c|c|c|c|c|}
\hline $\begin{array}{l}\text { Spearman } \\
\text { correlations }\end{array}$ & $\begin{array}{l}\text { Duration of } \\
\text { treatment }\end{array}$ & $\begin{array}{l}\text { No. of } \\
\text { drugs/ } \\
\text { day }\end{array}$ & $\begin{array}{l}\text { Frequency } \\
\text { of Drug } \\
\text { adm. }\end{array}$ & Adherence \\
\hline \multicolumn{5}{|l|}{ Duration of $\mathrm{Rx}$} \\
\hline $\begin{array}{l}\text { Correlation } \\
\text { Coefficient }\end{array}$ & 1.000 & 0.743 & 0.785 & 0.846 \\
\hline Sig. (2-tailed) & 0.000 & 0.000 & 0.000 & 0.000 \\
\hline $\mathrm{n}$ & 180 & 180 & 180 & 180 \\
\hline \multicolumn{5}{|l|}{ No. of drugs } \\
\hline $\begin{array}{l}\text { Correlation } \\
\text { Coefficient }\end{array}$ & 0.743 & 1.000 & 0.590 & 0.668 \\
\hline Sig. (2-tailed) & 0.000 & 0.000 & 0.000 & 0.000 \\
\hline $\mathrm{n}$ & 180 & 180 & 180 & 180 \\
\hline \multicolumn{5}{|l|}{ Frequency } \\
\hline $\begin{array}{l}\text { Correlation } \\
\text { Coefficient }\end{array}$ & 0.785 & 0.590 & 1.000 & 0.792 \\
\hline Sig. (2-tailed) & 0.000 & 0.000 & 0.000 & 0.000 \\
\hline $\mathrm{n}$ & 180 & 180 & 180 & 180 \\
\hline \multicolumn{5}{|l|}{ Adherence } \\
\hline $\begin{array}{l}\text { Correlation } \\
\text { Coefficient }\end{array}$ & 0.846 & 0.668 & 0.792 & 1.000 \\
\hline Sig. (2-tailed) & 0.000 & 0.000 & 0.000 & 0.000 \\
\hline $\mathrm{n}$ & 180 & 180 & 180 & 180 \\
\hline
\end{tabular}

Contrary to the common belief that adherence deceases with the increase in the number of prescribed medications; we found that adherence increases when the number of medications prescribed and the frequency of drug administration increases. We also found that adherence increases with increase in duration of treatment.

The adherence was significantly $(\mathrm{p}<0.05)$ and positively ( $\mathrm{rs}=0.792$ and 0.846 ) correlated to the frequency of drug administration and duration of treatment. Adherence was positively correlated to the number of drugs per day ( $\mathrm{rs}=0.668$ ) but the relation were not statistically significant $(p=0.102)$. All the correlations were large.

The likely reason for our observations may be that those who feel they are ill (for example, as a result of a significant number of drugs being prescribed) are more inclined to take the appropriate precautions to maintain or improve their health.

Shalansky and Levy in a study on effect of number of medications on cardiovascular therapy adherence found that taking fewer medications was associated with lower adherence with chronic cardiovascular regimens. The researchers concluded that the patients who had $\geq 3$ months of persistence with cardiovascular medications were capable of taking a large number of medications with a high level of adherence [8].

Billups et al. in a study on the relationship between drug therapy and non-compliance found that increased age, high number of chronic
Table 5: Regression analysis

\begin{tabular}{|c|c|c|c|c|c|c|c|}
\hline \multicolumn{8}{|c|}{ Model summary } \\
\hline Model & $\mathbf{R}$ & \multicolumn{2}{|c|}{ R Square } & $\begin{array}{l}\text { Adjusted } \\
\text { R Square }\end{array}$ & \multicolumn{3}{|c|}{ Std. Error of the Estimate } \\
\hline 1 & $0.851 \mathrm{a}$ & \multicolumn{2}{|c|}{0.723} & 0.719 & \multicolumn{3}{|l|}{0.27622} \\
\hline \multicolumn{8}{|c|}{ aPredictors: (Constant), Frequency, number of drugs, duration of treatment } \\
\hline \multicolumn{8}{|c|}{ ANOVA $^{\mathrm{a}}$} \\
\hline \multicolumn{2}{|l|}{ Model } & \multicolumn{3}{|c|}{ Sum of Squares df } & $\begin{array}{l}\text { Mean } F \\
\text { Square }\end{array}$ & & Sig. \\
\hline \multicolumn{8}{|l|}{1} \\
\hline \multirow{3}{*}{\multicolumn{2}{|c|}{$\begin{array}{l}\text { Regression } \\
\text { Residual } \\
\text { Total }\end{array}$}} & \multirow{2}{*}{\multicolumn{2}{|c|}{35.121}} & & \multirow{3}{*}{$\begin{array}{l}11.707 \\
0.076\end{array}$} & \multirow[t]{2}{*}{53.438} & \multirow[t]{2}{*}{$0.000 \mathrm{~b}$} \\
\hline & & & & 176 & & & \\
\hline & & \multicolumn{2}{|l|}{48.550} & 179 & & & \\
\hline \multicolumn{8}{|c|}{ 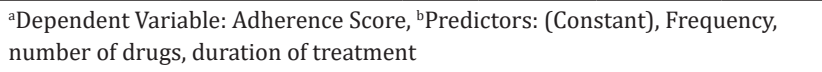 } \\
\hline \multicolumn{8}{|c|}{ Coefficients $^{\mathrm{a}}$} \\
\hline \multirow{2}{*}{\multicolumn{2}{|c|}{ Model }} & \multicolumn{3}{|c|}{$\begin{array}{l}\text { Unstandardized } \\
\text { Coefficients }\end{array}$} & $\begin{array}{l}\text { Standardized } \\
\text { Coefficients }\end{array}$ & \multirow[t]{2}{*}{$\mathbf{t}$} & \multirow[t]{2}{*}{ Sig. } \\
\hline & & B & Std. & I. Error & Beta & & \\
\hline \multicolumn{8}{|l|}{1} \\
\hline \multicolumn{2}{|c|}{ (Constant) } & 0.310 & 0.06 & & & 4.555 & 0.000 \\
\hline \multicolumn{2}{|c|}{ DURATION } & 0.292 & 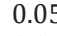 & & 0.466 & 5.703 & 0.000 \\
\hline \multirow{2}{*}{\multicolumn{2}{|c|}{$\begin{array}{l}\text { DRUGS } \\
\text { FREQUENCY }\end{array}$}} & 0.090 & 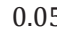 & & 0.103 & 1.645 & 0.102 \\
\hline & & 0.161 & 0.03 & & 0.344 & 5.176 & 0.000 \\
\hline
\end{tabular}

${ }^{a}$ dependent Variable: Adherence Score

conditions, and high number of concurrent drugs were positively correlated with medication adherence [9].

Tamrat et al. in a study on adherence in glaucoma found that taking multiple prescription medication was not associated with non adherence [10]. Monane et al. in a study on non-compliance in congestive cardiac failure observed that those taking concurrent ACE inhibitor or diuretic therapy along with digoxin had better adherence [11].

\section{Limitations}

Measurement of medication adherence is quite challenging. There are numerous tools available for measurements which identify different components of non-adherence.Currently, none of the available methods of measurement can be considered as gold standard. The parameters of acceptable adherence need to be carefully delineated and appropriated for individual situations. In our study, there are some limitations in terms of adherence measurement methods, study design, and inconsistency in adherence definitions.The validity of our findings relies primarily on the accuracy of responses. We tried to minimize recall bias using a well-structured pre-validated questionnaire. Another limitation of this study is the limited sample size. The design of the study does not ensure 
that the study population is representative of general population. Due to the variations in measurement methods and study designs the direct comparisons are difficult. The present study is only exploratory in nature. Well-designed large-scale studies with rigorous measurement strategy would be worthwhile to confirm these associations.

Moreover in chronic conditions, the effect of medication complexity may take many years to show its effect on adherence. Therefore the results of this study should be taken with caution.

\section{CONCLUSIONS}

Medication complexity is challenging. Medication regimen becomes complex when a person is given many medications, each with its dosing regimen, without adequate supervision or assistance. The findings of studies examining the relationship between medication complexity and adherence are mixed. Our findings may not entirely explain why people who take more drugs are more likely to be adherent. These findings may be specific to this group. Future studies that examine a wide range of potential impacts of complex drug regimens on adherence are needed for a better understanding.

\section{ACKNOWLEDGMENT}

The authors would like to express their sincere thanks and gratitude to Dr. Atta Abbas Naqvi and Professor Mohamed Azmi Hassali, of Discipline of Social and Administrative Pharmacy, School of Pharmaceutical Sciences, Universiti Sans Malaysia (USM), Penang, Malaysia, for allowing the use of GMAS in this study. The authors also wish to thank the patients who participated in the study.

\section{AUTHORS' CONTRIBUTIONS}

All authors have made considerable contributions to the work reported in the manuscript.

\section{CONFLICT OF INTEREST}

None.

\section{AUTHORS` FUNDING}

None.

\section{ETHICAL APPROVAL}

Yes.

\section{REFERENCES}

1. World Health Organization. Adherence to Long-Term Therapies: Evidence for Action. Geneva: World Health Organization; 2003.

2. Brown MT, Bussell JK. Medication adherence: WHO cares? Mayo Clin Proc 2011;86:304-14.

3. Gast A, Mathes T. Medication adherence influencing factors-an (updated) overview of systematic reviews. Syst Rev 2019;8:1-17.

4. Feenstra J, Grobbee DE, Jonkman FA, Hoes AW, Stricker BH. Prevention of relapse in subjects with congestive heart failure: The role of precipitating factors. Heart 1998;80:432-6.

5. Kim SJ, Kwon OD, Han EB, Lee CM, Oh SW, Joh HK, et al. Impact of number of medications and age on adherence to antihypertensive medications:A nationwide population-based study. Medicine 2019;98:e17825.

6. Naqvi AA, Hassali MA, Rizvi M, Zehra A, Iffat W, Haseeb A, et al. Development and validation of a novel general medication adherence scale (GMAS) for chronic illness patients in Pakistan. Front Pharmacol 2018;9:1124

7. Andrew WR, Ginny DC, Denise AE, Mary TR, Morris W, Joel FF. Patterns of medication adherence and health care utilization among patients with chronic disease who were enrolled in a pharmacy assistance program.N C Med J 2014;75:310-8.

8. Shalansky SJ, Levy AR. Effect of number of medications on cardiovascular therapy adherence. Ann Pharmacother 2002;36:1532-9.

9. Billups SJ, Malone DC, Carter BL. The relationship between drug therapy noncompliance and patient characteristics, health-related quality of life, and health care costs. Pharmacotherapy 2000;20: 941-9.

10. Tamrat L, Gessesse GW, Gelaw Y. Adherence to topical glaucoma medications in Ethiopian patients. Middle East Afr J Ophthalmol 2015;22:59-63.

11. Monane M, Bohn RL, Gurwitz JH, Glynn RJ, Avorn J. Noncompliance with congestive heart failure therapy in the elderly. Arch Intern Med 1994;154:433-7. 